\title{
O RÁDIO NOSSO DE CADA DIA
}

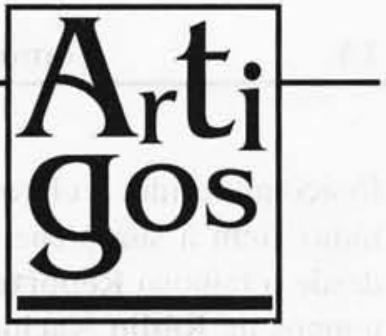

nacionais

\section{Rádio, o mais abrangente veículo de comunicação presente no cotidiano de todos nós, embala sonhos, desperta emoções e pode ajudar no trabalho educativo}

Muitas vezes um objeto, um fato são tão cotidianamente participantes da nossa vida que, paradoxalmente, não os percebemos nem lhes damos importância. Assim é o rádio, travestido de formas variadas, mas sempre presente em nosso dia-a-dia: rádio relógio; rádio toca-fita ou $\mathrm{CD}$; acoplado ao possante "três em um" da sala; receptores $\mathrm{AM} / \mathrm{FM}$ de tamanhos e formatos diversos espalhando-se por toda a casa; rádio portátil a pilha liberado da eletricidade que cerceava suas andanças por aí; rádio que anda de carro e de caminhão por este mundo de Deus; rádio que chega suave no som ambiente sofisticando alguns locais de trabalho; rádio grandão, exibido, troféu primeiro da conquista do migrante do interior na cidade grande. Rádio que viveu momentos de glória ao ocupar lugares de destaque na sala das casas da nossa infância, unindo a família nas radionovelas, nos programas de auditório, na música, no humor, no esporte, no noticiário. Rádio que foi usado por ditadores, como Hitler, de forma primorosa para fazer acreditar que suas idéias ergueriam a nação alemã e colocariam em supremacia mundial o seu povo.

Ainda em nossos dias, presidentes e o próprio Congresso Nacional contam com redes radiofônicas para, de alguma forma, dar satisfação ao povo de seus atos, ao tentar justificá-los. Mas esta é uma longa história, que não será tratada aqui nesta nossa conversa, que não é "ao pé do ouvido"...

Antes de qualquer abordagem pedagógica ou de considerações sobre pontos que possam nortear uma educação para o meio, vamos a uma panorâmica sobre o rádio para conhecer um pouco mais esse amigo que, de tão íntimo e presente na nossa vida, nem lhe damos a atenção devida.

\section{BRASILEIRO NÃO VIVE SEM RÁDIO}

Bem, o brasileiro acorda... e liga o RÁDIO! Daí em diante, ele não é mais o mesmo - os acontecimentos considerados destaques de sua cidade, país ou do mundo, chegam-lhe através do seu noticiário radio-

\section{A AUTORA}

Marlene M. Blois

Especialista em radiodifusão educativa. Coordenadora de Extensão do Centro de Filosofia e Ciências Humanas da UFRJ e da Central de Tecnologia em Comunicação da Escola de Comunicação da UFRJ. Produz e apresenta o programa radiofônico Educação em Debate. 
fônico preferido. É claro que "o que deu no rádio" tem a sua plena credibilidade, isto desde o famoso Repórter Esso dos áureos tempos da Rádio Nacional. Uma voz macia mas incisiva, que entende "a alma feminina", fala para a dona de casa e para todas as mulheres da cidade. Na programação das emissoras, começa o horário dedicado às rainhas do lar, muitas vezes sem rei nem coroa!

Rádio é coisa de jovem? Como se portam a "gatinha" e o garotão frente à magia desse senhor que já fez 70 anos? Sintonizar naquela FM/AM é coisa de "careta" — fala a galera. Os jovens, sem dúvida, incorporaram o rádio a seus espaços de vida e o adotaram dentro e fora de casa. Percebe-se que as rádios se convertem em um símbolo de diferença, juntamente com a música ou pela música.

$\mathrm{Na}$ casa ao lado, como em tantas outras, a Bíblia conforta e ajuda a entender este mundo louco. A "igreja eletrônica" entra em ação, fazendo a cabeça de seus seguidores, não importa se católicos, evangélicos ou de uma certa igreja que tenta desmoralizar um certo império das telecomunicações.

Não importa se a preferência do ouvinte recaia em uma emissora em Ondas Médias (OM), Curtas (OC) ou Tropicais (OT) ou se a opção é pelo som puro de uma FM (Freqüência Modulada). O que ele quer do rádio é a notícia em primeira mão, a cobertura do fato in loco. Quer a prestação de serviços variados, busca orientação de como fazer chegar a sua reclamação à defesa do consumidor, quer música, muita música, do forró à ópera, do jazz à bossa nova, do funk à canção francesa. Em uma noite de insônia, precisa da companhia dos comunicadores da madrugada. Se o problema é acertar o relógio atrasado, é só ligar o rádio que a hora certa está lá.
E o futebol? Ah, o jogo narrado pelo locutor esportivo que sabe tudo sobre a "paixão nacional"! É pura adrenalina, emoção, é saber que não se está só na torcida, porque os milhares de torcedores estão unidos naquela "corrente pra frente", sofrendo, empurrando o time, na magia que só o rádio é capaz de construir. E melhor do que assistir ao jogo pelo rádio, só mesmo indo ao estádio.

$\mathrm{O}$ ouvinte ainda quer um rádio lúdico com programas humorísticos, com brincadeiras dos comunicadores, com a letra irreverente do samba e do funk, porque a vida está dura, o dinheiro cada vez mais curto, a violência faz ponto em cada esquina.

Para não ser um analfabeto também da informação, é preciso ligar o rádio e buscar ajuda para entender as tantas mudanças de valores e de comportamentos. E como já compreendeu que o mundo é muito maior do que o seu município e o seu estado, então ele, ouvinte, no meio de tanta notícia, não pode desconhecer o que seja o Mercosul, as razões das lutas seculares entre árabes e judeus.

O que hoje na verdade existe é uma programação oferecida por cerca de 2.550 emissoras de rádio em todo o Brasil, para quase 80 milhões de domicílios particulares permanentes que possuem aparelhos receptores.

Este fantástico parque radiofônico tem um público potencial de 123.896 .828 moradores, de um total de 147.057.930 brasileiros, segundo o IBGE, excluídos, em ambos os dados, os residentes da zona rural do Acre, Amazonas, Roraima, Pará e Amapá.

Sem dúvida alguma, José Carlos Araújo, o Garotinho criativo e competente locutor esportivo da Rede Globo de Rádio, tem toda razão: "brasileiro não vive sem rádio". E eu acrescento ao slogan: e o rádio não pode abrir mão de 123 milhões de brasileiros! 


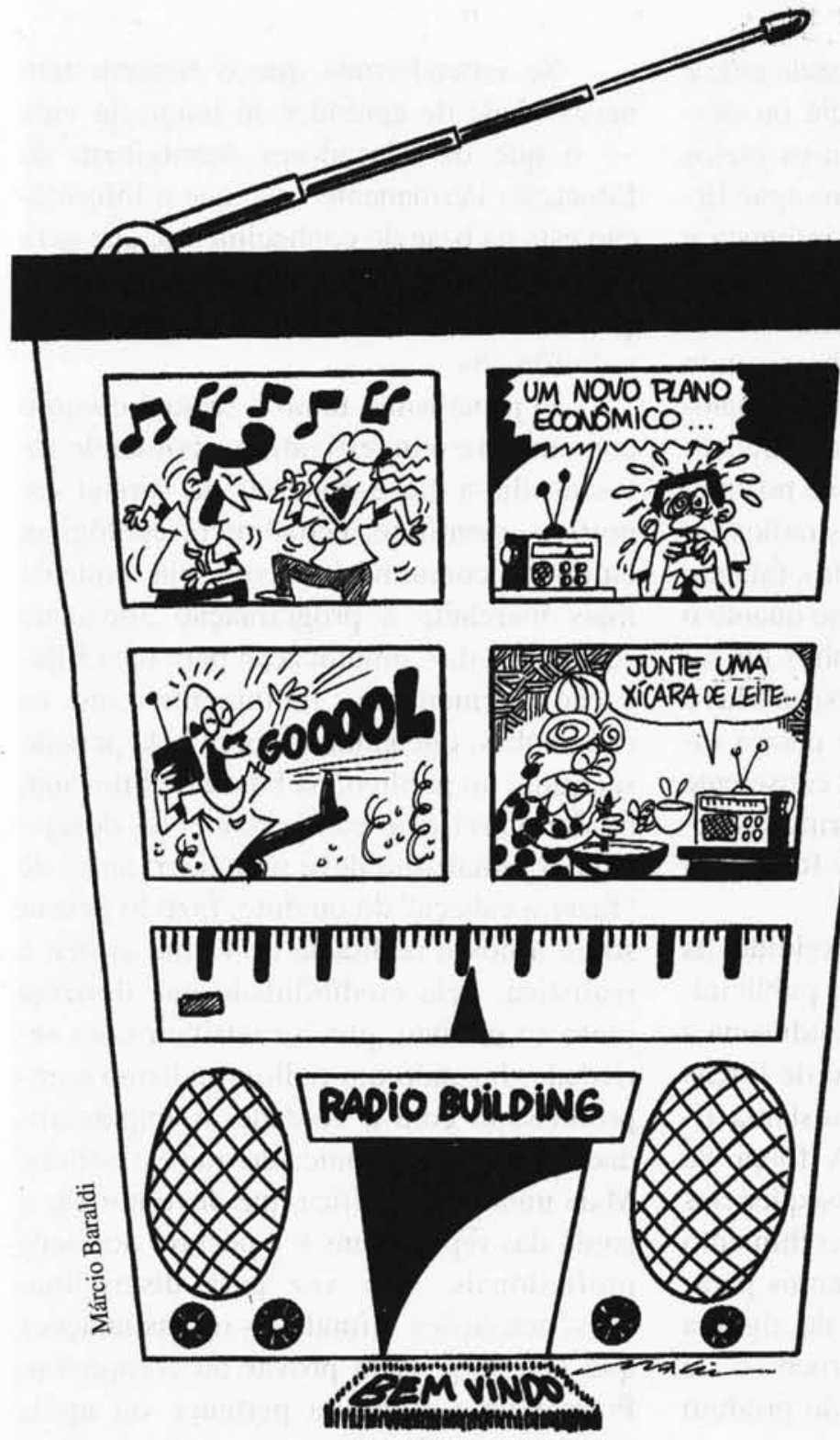

vendo e ouvindo o mundo através do rádio e da TV. O que acontece nas muitas latitudes do nosso planeta está diariamente na mídia eletrônica, mas vai ter que esperar até o dia seguinte para sair nos jornais e algum tempo para chegar aos livros didáticos e estes às escolas.

Quem se liga no seu radinho todos os dias é, de alguma forma, partícipe dos fatos que acontecem. Para muitos dos ouvintes, analfabetos ou não, o rádio se constitui, muitas vezes, no único canal de informação, de conhecimento e de ligação mais ampla com universos distanciados do seu quintal comunitário. Cada um no seu mundinho cresce na e com a informação e, assim, vai incorporando conhecimentos à sua bagagem, antes restrita ao tão próximo que se confundia com a própria família e vizinhança.

Não dá para tapar os ouvidos e pensar que nada mudou, princi-

NAS "ENTRELINHAS" DA PROGRAMAÇÃO

Com mais de um bilhão de aparelhos de TV e três vezes, no mínimo, este número de receptores de rádio no mundo, pode-se afirmar que o homem do final do Século XX experiencia a História do seu tempo palmente nos últimos dez anos, para não recuar muito no tempo. Até o rádio, o nosso rádio de cada dia, mudou. Se o número de emissoras cresceu bastante nos últimos tempos, hoje é possível dizer genericamente: "diga-me que rádio ouves, que eu te direi quem és". E aí entra a força do marketing, tentando de todo jeito ganhar o ouvinte, covencendo-o de que a programação da emis- 
sora foi feita especialmente pensando nele e para ele. Sem nenhuma inocência ou descompromisso, como todos os outros meios de comunicação de massa, o rádio segue firmando-se como o veículo mais intimista e de maior mobilidade, aqui e em qualquer parte do mundo. Compondo sistemas ou redes com outras emissoras ou sobrevivendo com independência, se seus objetivos maiores são comerciais, evangélicos ou educativos, se a linha gerencial centra-se no interesse do dono ou comunidade, as rádios fazem parte do dia-a-dia do brasileiro, falando a linguagem que tanto $o$ analfabeto quanto $o$ letrado entendem, vendendo sonhos ou sabonetes, música sertaneja ou clássica. Mas é preciso, no entanto, ficar atento para a intenção - assumida ou velada, consciente ou não - de quem produz, informa e seleciona a notícia, a música ou o que for que vá ao ar pelas ondas do rádio.

E de que vivem as rádios, excluídas as educativas? Da venda de espaços publicitários em suas programações e da audiência a seus programas. Esta conjugação de forças - patrocinadores/ouvintes - sustenta financeiramente as emissoras. A força de venda do veículo tem como consequiências óbvias: mais empregos, mais recolhimento de impostos, além de envolvimentos paralelos com outras empresas que de alguma forma se relacionam com o processo de produção e de comercialização do produto ou serviço.

O que se quer é ética na oferta, honestidade no que é anunciado, garantia dos direitos do consumidor, porque divulgar, tornar conhecido, ajudar a vender um produto não é pecado e se inspira em noções como individualismo e livre empresa...
Se entendermos que o homem tem necessidade de aprender ao longo da vida - o que os educadores denominam de Educação Permanente - e que a informação está na base do conhecimento, que gera reflexão e crítica, podemos identificar traços educativos em muitos dos programas radiofônicos.

O jornalismo, tanto o factual como o comentado e o investigativo, abordando fatos do dia-a-dia e matérias de caráter esportivo, científico, econômico, ecológico, cultural e comunitário talvez seja o que de mais marcante a programação apresente sob a ótica da Comunicação para uma Educação Permanente. Juntamente com as campanhas, que ganham força pela persuasão junto ao público, na busca de informar, mudar ou reforçar comportamentos desejáveis, o jornalismo deve pretender, antes de "fazer a cabeça" do ouvinte, fazê-lo pensar sobre a nossa realidade de forma crítica e realística. Pela credibilidade que desfruta junto ao público, precisa retribuir com seriedade, fazendo um radiojornalismo compromissado com a verdade. A imparcialidade precisa ser a tônica do que é a notícia. Mais uma vez é a ética que deve nortear a pauta das reportagens e a postura dos seus profissionais, sem vez para discriminações, acusações infundadas ou insinuações que não se possam provar ou comprovar. Porque uma emissora pertence ou apóia um determinado grupo, não pode escamotear fatos que o desfavoreçam, faltando com seu compromisso maior, que é a veracidade da informação e não manipulação de dados.

A programação de música popular ou erudita, além de entreter o ouvinte, leva-o a conhecer a criação artística do setor, extrapolando fronteiras nacionais ou culturais. Na verdade, que veículo torna 
um cantor, compositor ou música conhecidos nacionalmente senão o rádio? Pense nisso... Mas não se esqueça da aculturação, principalmente dos jovens, pela música, os quais curtem mais as bandas e cantores americanos do que os nossos. Grave, não?

E os programas que prestam serviços ou são considerados de utilidade pública? Além de realçar valores e atitudes "desejáveis", criam laços de solidariedade, humanizam a cidade, destacam a consciência de que nem tudo está perdido em meio ao individualismo e à violência dos grandes centros. O sentido de pertencer à comunidade imaginada começa quando o ouvinte liga e se liga no rádio. E sente que está com muitos, com outros, mesmo que ninguém se conheça, não importa. O que vale é a não passividade diante do ouvido. Respostas precisam ser buscadas para indagações como: que valores e atividades são consideradas "desejáveis" pela sociedade? Há discriminações, seja nos serviços prestados ou no pedido da colaboração dos ouvintes para causas diversas? Às vezes o que, à primeira vista, se configura como uma questão comunitária, envolve interesse muito mais pessoal do que coletivo.

Mas o que passa desapercebido à maioria e que tem sido a grande força do rádio é, ao explorar o filão da oralidade, "ensinar" informalmente, sem regras ou dicionário, um certo padrão da língua portuguesa aos seus falantes brasileiros e, assim, contribuir para que tenhamos uma certa unidade de fala, sem negar ou desprezar a diversidade e as expressões locais e regionais, de Norte a Sul do país. Sotaques e falares à parte, os comunicadores se entendem muito à vontade com o seu público, de forma coloquial e prazerosa, sem as barrei- ras que poderiam se originar do uso inadequado da língua.

A força comunicacional do idioma comum a todos ganha sua maior expressão, enquanto alcance de massa, no rádio. Seus profissionais lançam slogans logo assimilados pelos ouvintes, criam expressões e gírias, trabalham criativamente com palavras, a matéria prima da linguagem radiofônica.

Cada emissora marca seu próprio estilo, seu padrão de locução solto, descontraído, provocativo ou formal, impessoal. Esta é uma das mais ricas leituras do veículo que se pode ter no trabalho de educar para o rádio. Porque as palavras podem ser coloridas e enriquecidas com sons os mais variados, compondo um todo indissolúvel, ganhando novo significado, sendo um outro significante.

Aqui ainda se pode abrir espaço para as "assinaturas" musicais das emissoras, vinhetas e sufixos dos programas. Há unidade entre todos esses sons que identificam e anunciam o que irá ao ar? Estabelecem relação direta com a proposta do que vai ser veiculado? De que recursos sonoros e tecnológicos se valem? Um campo enorme para se analisar no vastíssimo mundo de códigos radiofonicamente usados.

$\mathrm{E}$ as vozes que nos chegam de cada emissora, como são? Qual a predominância - femininas ou masculinas? Jovens ou maduras? Interpretativas, dramáticas, irônicas, alegres ou imparciais, sóbrias, parecendo terem todas o mesmo timbre e igual entonação? Se a voz é instrumento de comunicação, também deve ser analisada na leitura global do que oferece esta ou aquela emissora. 


\section{A CONSTRUÇÃO DAS IMAGENS}

O rádio trabalha com sons e com a palavra falada, ingredientes fortes o suficiente para fazer de cada ouvinte um construtor individualizado de imagens, das suas imagens. Sem apresentar qualquer aparato visual - como o cinema, a televisão, o teatro ou o jornal - o rádio, por isso mesmo, vai mexer com a imaginação de cada um, com a realidade de cada um e sua visão de mundo, fazendo de cada receptor um co-autor do que vai ao ar. É que, fantasticamente, os sons emitidos - músicas gravadas ou tocadas ao vivo, ruídos que ambientam, criam ou recriam cenas e fatos, a voz dos que falam tanta coisa (locutores, locutoras; atores, atrizes; comunicadores, comunicadoras; repórteres, noticiaristas, comentaristas; cantores, cantoras) todos os dias; o que e como os profissionais do rádio comunicam, em sua versão elegida e editada dos acontecimentos, neste caso da própria história que se faz cotidianamente. Ou mesmo na interpretação da carta de outro ouvinte ou de um poema de Drummond, todos estes são componentes básicos e detonadores da criatividade do ouvinte, que constrói imagens únicas, ampliando a sua própria experiência e bagagem, em uma interatividade silenciosa mas nem por isso desprovida de forte participação. Algo incrível que o rádio proporciona aos que, valendo-se somente da audição, podem, mágica e criativamente, ter seus outros sentidos acionados, em um envolvimento global com a "cena" radiofônica.

Há que se destacar que a codificação e decodificação da mensagem radiofônica passa, além da criação individualizada de imagens, pela recepção também pessoal, que abre possibilidades de leituras íntimas e diversificadas.

\section{RÁDIO EDUCATIVAS: A CIDADANIA COMO DEFINIÇÃO}

Depois de uma panorâmica sobre o rádio, sua linguagem e seus recursos, sua programação e fonte de sobrevivência, falta enfocar aqui um tipo particular de emissoras classificadas de educativas.

O rádio, no Brasil, surge em 1923, da iniciativa do pioneiro Roquette Pinto, criado para levar educação e cultura ao povo, com a Rádio Sociedade do Rio de Janeiro (hoje Rádio MEC-AM, Rio de Janeiro).

No entanto, "não se pode conceber as emissoras educativas de rádio e TV formando um para-sistema no complexo conjunto dos meios de comunicação. Elas são parte dele e toda vez que lhes dão contornos estranhos, são alijadas pelo públicol".

Então, qual a grande diferença entre as comerciais e as educativas, além, é claro, do que é "visível" na programação: a inexistência de publicidade nas educativas. É a intencionalidade do fazer radiofônico. Colocando ou não no ar cursos e aulas, toda a proposta de sua programação é vinculada à construção da cidadania e seu exercício democrático.

No contexto das educativas ganham espaço próprio as emissoras universitárias ${ }^{2}$, pelo potencial que trazem ao estarem vinculadas a uma instituição de múltiplas finalidades educativas. As rádios podem ser o elo de aproximação da Universidade com a comunidade, em ações de mão dupla, fazendo com que ambas se conheçam mais e melhor, interajam em áreas de interesse comum. $\mathrm{O}$ campo é vasto tanto para projetos de educa-

1. BLOIS, Marlene. Rádios educativas: caminhando contra o vento. Tecnologia Educacional. v.22 (113-114), jul/out. 1993.

2. BLOIS, Marlene. Rádios e TV Universitárias - uma proposta em discussão. Comunicação e solidariedade. São Paulo: Loyola, 1992, p.107-111. 
ção formal como atualização e formação de recursos humanos, quanto para os não-formais, como organização comunitária, educação para saúde e mobilização para atividades coletivas. Com certeza a Universidade tem muito a aprender fora dos muros do campus, falando pela rádio com os que lhe são diferentes...

Vale destacar a produção radiofônica educativa, acumulada ao longo dos anos, do Departamento Nacional de Rádio Educativa Roquette Pinto, da Fundação Roquette Pinto, DNRERP/FRP, atualmente vinculada à Secretaria de Comunicação Social da Presidência da República. Do seu acervo, fazem parte produções recentes, como o Curso para Professores Alfabetizadores de Crianças (em co-produção com a Associação Brasileira de Tecnologia Educacional - ABT); o Curso para Educadores Leigos (co-produção com o CEN - Centro Educacional de Niterói); e as séries: Encontros com Paulo Freire $^{3}$, Nós na Escola, Onda Viva - a Pós-Modernidade na Escola, Alfabetizações na Escola, Educação em Revista e Momento em $\mathrm{Foco}^{4}$. Para os profissionais que trabalham com pessoas portadoras de deficiências, oferece duas séries: Nosso Tempo e Educação Física Adaptada.

A primeira série que abre espaço no rádio para discutir questões do dia-a-dia sob a ótica da educação, Educação em Debate, foi uma iniciativa do DNRERP/FRP e está há dez anos no ar.

Já foram produzidos mais de 340 programas, abordando temáticas variadas, tendo como público prioritário, mas não ex- clusivo, os profissionais de Educação, como demonstra a correspondência recebida dos ouvintes.

Vale lamentar a suspensão do convênio entre o MEC e a ABERT - Associação Brasileira de Emissoras de Rádio e TV, que abria espaço nas emissoras comerciais, gratuitamente, para a veiculação de programas educativos. Perde o seguimento de público que mais precisa de educação aberta e a distância...

\section{TRABALHO COM ALUNOS}

Bem, acredito que esse conjunto de informações sobre o rádio possa vir a facilitar um trabalho educativo não só voltado para o veículo como, também, para questões relacionadas aos meios de comunicação de massa. Isso porque não é possível estudar um meio sem contextualizá-lo - no tempo e no espaço - e conhecer como convive com os demais. Assim, as propostas e sugestões a seguir devem considerar o nível do grupo para o qual se dirigem as atividades e as condições materiais que viabilizam sua execução. As adaptações, portanto, são desejáveis.

1. Linha de tempo sobre a história do rádio (envolvendo pesquisas)

- A invenção do rádio

- O rádio no Brasil

- $\mathrm{O}$ rádio em nossa cidade/estado

2. Entrevistas, que podem ser gravadas ou não

- Com pessoas com mais de 40 anos:

Como era o rádio na sua infância?

3. A série Encontros com Paulo Freire foi uma co-produção Rádio Cultura/SP - Rádio MEC/RJ, tendo como entrevistadores Toninho de Moraes e Marlene Blois. Além das duas emissoras, o Grupo Veredas/SP também possui cópia dos 15 programas de 30 minutos de duração.

4. Para maiores informações sobre as produções educativas acima citadas, contatar diretamente: DNRERP/FRP - Praça da República, 141 A, Rio de Janeiro/RJ, CEP 20211-350. Tel/Fax.: (021) 2426328. 
Que programas tinham maior audiência?

Que lembranças o(a) Sr.(a) guarda do rádio e de seus artistas?

\section{- Com jovens}

Quando você ouve rádio?

Você sintoniza sempre a mesma emissora? Por quê?

Na sua casa, quem ouve rádio? Que emisso$\mathrm{ra}(\mathrm{s})$ preferem?

Você estuda ouvindo rádio?

E você, o que gosta no rádio?

Qual o seu programa preferido?

Quanto tempo, por dia, você ouve rádio?

\section{- Com homens e mulheres (ouvintes)}

$\mathrm{O}$ (A) Sr.(a) ouve rádio?

Que emissora prefere? Por quê?

Em que horário ouve rádio?

Quantos aparelhos de rádio tem em sua casa? $\mathrm{O}$ (A) Sr.(a) gosta dos programas especialmente dirigidos ao público masculino/feminino? Por quê?

Qual o seu programa preferido?

Que programa o(a) Sr.(a) gostaria que fosse oferecido pelas nossas rádios?

$\mathrm{O}$ rádio tem a sua credibilidade?

\section{- Com anunciantes}

Por que o(a) Sr.(a) anuncia no rádio?

Qual o retorno comercial que o veículo apresenta?

3. Levantamento dos meios de comunicação disponíveis

- Jornais/ revistas

- Emissoras de rádio

- Emissoras de TV

- Serviços de alto-falante

\section{Informação a levantar:}

- Nome/endereço/telefone

- Vinculação (ex.: Cada meio pertence a um dono ou um dono detém mais de um meio? A rádio ou TV são filiadas a algum sistema ou não? A comunidade dispõe de algum meio, como jornal ou serviço de alto-falante?)

- Jornais/revista: periodicidade (jornal diário, semanal, mensal; matutino, vespertino; revista mensal, bimensal); aquisição (venda, distribuição gratuita); público (aberto, dirigido) - Rádios: AM? FM? OC? OT?; localização no dial; pública; comercial, educativa ou comunitária; horário de veiculação.

4. Estudo da programação (AM/FM/OC/OT) - Escuta de faixas horárias

Ex.: de 7 às $10 \mathrm{~h} ; 10$ às 13 etc.

- Levantamento dos programas veiculados nas faixas horárias identificando: apresentador(a) ou locutor(a), público, formato dos programas, anunciantes, recursos utilizados etc.

5. Radiojornalismo

- Duração do programa

- Abrangência do noticiário: local, regional, nacional, internacional

- Reportagens/repórter

- Seqüências de notícias

- Recursos sonoros utilizados

- Inserções na programação

No caso do Radiojornalismo, depois do estudo indicado, é interessante cotejar o que foi noticiado e como foi, com o que irá ser publicado no jornal do dia seguinte ou mesmo levado ao ar pela TV.

6. Rádio-recreio

- Produção de programas pelos alunos (noticiário, reportagens, entrevistas, prestação de serviços, utilidade pública, informativos diversos, música) para veiculação por altofalante para os alunos de cada turno.

- Ampliação do tempo de veiculação (antes da entrada, na mudança de turno, na hora da 
saída, em dias de festa) como decorrência do interesse e das condições de produção.

- Análise do processo de produção, desde a "linha editorial", passando pela "seleção" dos assuntos, escolha do formato mais adequado, censura aberta ou velada, competência de cada "profissional", elaboração do roteiro (script), criação de vinhetas, créditos (identificação da equipe) e agradecimentos.

Muito mais se tem para trabalhar, quando o meio é o rádio. Algumas indicações podem ser tiradas do próprio texto, principalmente nos pontos referentes à linguagem radiofônica e à criação de imagens. Sem descuidar de levar os alunos à leitura da intencionalidade do que é veiculado, seja aumentar as vendas do refrigerante em promoção no supermercado - a mais claramente decodificada - há muitas outras, que dão aos meios de comunicação tal força que são considerados o quarto poder, nos tempos modernos.
Agora...se ligue nesta pergunta final - há uma emissora educativa em seu município? Não? E você sabe se no Plano Básico de Distribuição de Canais em FM existe um canal reservado para fins educativos?

Se você considera importante ter uma FM com essa característica, procure se informar. Com certeza, mobilizar a comunidade para viabilizar esta proposta não será coisa do outro mundo. Afinal, o rádio tem a credibilidade da maioria, todos querem um quadro verde-esperança para a Educação e experiências em muitos países - inclusive $o$ nosso - provam que o rádio pode informar, educar, ensinar e entreter. Então? O que você está esperando? Lembre-se sempre: "o bra-

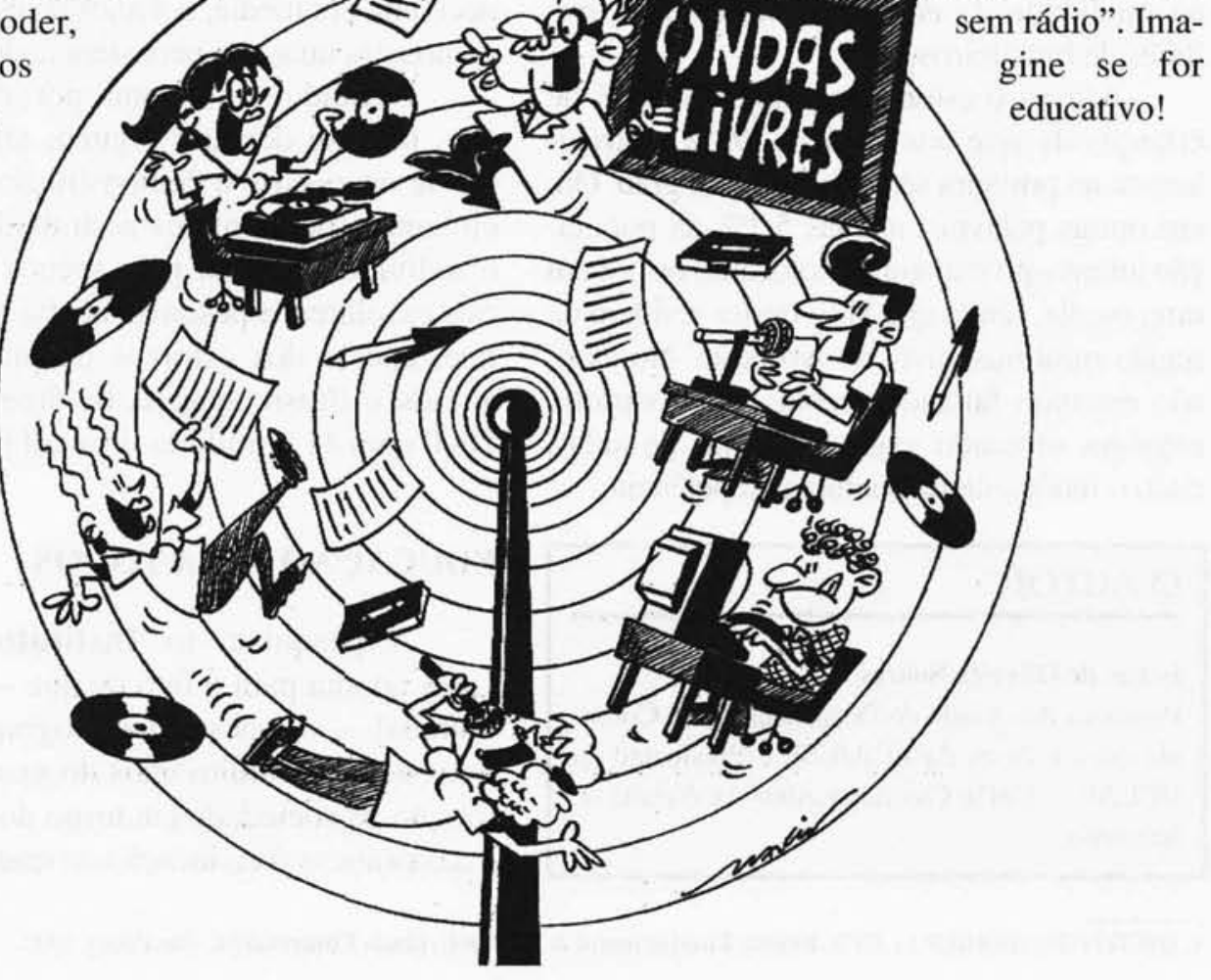

